\title{
Treatment advances in Alzheimer's disease based on the oxidative stress model
}

\author{
Avi L Friedlich ${ }^{1}$, Raj K Rolston ${ }^{2}$, Xiongwei Zhu ${ }^{3}$, Michael W Marlatt ${ }^{4,5}$, \\ Rudy J Castellani ${ }^{6}$, Akihiko Nunomura ${ }^{7}$, Hyoung-gon Lee $^{3}$, \\ Gemma Casadesus ${ }^{8}$, George Perry ${ }^{3,9}$ and Mark A Smith ${ }^{3 *}$
}

\begin{abstract}
Addresses: ${ }^{1}$ Department of Psychiatry, Massachusetts General Hospital, Harvard Medical School, 50 Staniford Street, Boston, MA 02114, USA; ${ }^{2}$ Department of Pathology and Laboratory Medicine, Geisinger Medical Center, 100 N Academy Avenue, Danville, PA 17822, USA; ${ }^{3}$ Department of Pathology, Case Western Reserve University, 2103 Cornell Road, Cleveland, OH 44106, USA; ${ }^{4}$ Swammerdam Institute for Life Sciences - Center for Neuroscience, University of Amsterdam, Science Park 904, 1098 XH Amsterdam, The Netherlands; ${ }^{5}$ Marie Curie Early Stage Training Program NEURAD Graduate School, Göttingen, Germany; ${ }^{6}$ Department of Pathology, University of Maryland, 22 South Greene Street, Baltimore, MD 21201, USA; ${ }^{7}$ Department of Neuropsychiatry, Interdisciplinary Graduate School of Medicine and Engineering, University of Yamanashi, 1110 Shimokato, Chuo, Yamanashi 409-3898, Japan; ${ }^{8}$ Department of Neurosciences, Case Western Reserve University, 2109 Adelbert Road, Cleveland, OH 44106, USA; ${ }^{9}$ College of Sciences, University of Texas at San Antonio, One UTSA Circle, San Antonio, TX 78249, USA

* Corresponding author: Mark A Smith (mark.smith@case.edu)

FI000 Medicine Reports 2009, I:54 (doi:10.34I0/MI-54)
\end{abstract}

The electronic version of this article is the complete one and can be found at: http://FI000.com/Reports/Medicine/content/I/54

\begin{abstract}
Effective therapy for Alzheimer's disease (AD), up to this point, has been hampered by our inability to diagnose the disease in its early stages, before the occurrence of significant neurodegeneration and clinical symptoms. Because AD historically has been defined by neuropathologic criteria, treatment strategies have been aimed at diminishing the pathologic end result of the disease process, namely neurodegenerative changes associated with extracellular amyloid-beta-containing plaques, as well as intracellular neurofibrillary tangles of the hyper-phosphorylated microtubule protein, tau. While these avenues continue to be pursued, results thus far have been disappointing. It is now understood that oxidative stress plays a key role in the shared pathophysiology of neurodegenerative diseases and aging. For experimental treatment of $A D$, the focus of research and development efforts is increasingly shifting to target mechanisms of oxidative stress. Most recently, dimebon, whose mechanism of action relates to improved mitochondrial function, has emerged as a promising candidate for experimental treatment of $A D$.
\end{abstract}

\section{Introduction and context}

While Alzheimer's disease (AD) has been defined largely through molecular mechanisms of neuronal dysfunction, there is growing evidence indicating that oxidative stress and reactive oxygen species (ROS) contribute to dementia. Oxidative stress refers to cellular damage mediated by toxic ROS, the formation of which is due to an imbalance between ROS production and the capacity for removing ROS. ROS normally are produced as part of well-characterized metabolic pathways of oxidative phosphorylation during cellular respiration. Free radicals, generally unstable and highly reactive, are removed by specific detoxifying enzymes. With age, increased metabolic demand, and diseases (including $\mathrm{AD})$, there is increased oxidative insult, heightened superoxide radical formation, and increased superoxide dismutase levels which may cause $\mathrm{H}_{2} \mathrm{O}_{2}$ to diffuse through the mitochondrial membrane to the cytoplasm. Most free radicals are produced by mitochondria, and mitochondrial abnormalities in $\mathrm{AD}$ have been associated with deficiencies of the enzymes of the Krebs cycle, which may either increase free-radical production or alter 
the mechanism for their clearance [1-5]. Redox-active transition metals aberrantly accumulate in AD-susceptible neurons [6], and increased cytoplasmic $\mathrm{H}_{2} \mathrm{O}_{2}$, in the presence of redox-active metals and amyloid-beta (AB), may cause localized increased ROS concentration [7-9]. Increased ROS results in oxidation of lipids and RNA.

Studies suggest that there are multiple mechanisms by which oxidative stress may accumulate and create dysfunctional neuronal responses in $\mathrm{AD}$ and that development of the $\mathrm{AD}$ phenotype requires multiple insults [10-12]. Ischemia, inflammation, and aging are all pro-oxidant conditions. The brain, with its high oxygen use and a consumption of approximately $10 \%$ of cardiac output, depends on a number of cellular and tissue-specific antioxidant mechanisms for removal of the resultant by-product of ROS. When these mechanisms are ineffective or dysregulated, there is characteristic cellular injury.

The blood-brain barrier (BBB), critical to normal neuronal function (including synaptic transmission, remodeling, angiogenesis, and neurogenesis [13]), is also substantially compromised in a subpopulation of $\mathrm{AD}$ patients [14]. This may be a consequence of endothelial cell injury and dysfunction. One result may be impaired $A \beta$ transport to and from the brain via the receptor for advanced glycation endproducts (RAGE) and transcytosis of $A \beta$ into the brain parenchyma, where it binds to neurons and may enhance formation of toxic ROS.

\section{Current treatment options}

The current drugs approved by the US Food and Drug Administration (FDA) to treat $\mathrm{AD}$ are the acetylcholinesterase (AChE) inhibitors, such as donepizil, and the $N$-methyl-D-aspartate (NMDA) receptor antagonist, memantine. These drugs are aimed at symptomatic improvement in cognitive ability and are marginally effective $[15,16]$. The AChE inhibitors are designed to enhance cholinergic neurotransmission by reducing breakdown of acetylcholine (ACh) in the synaptic cleft. The benefit of AChE inhibitors is thought to relate to the role of ACh in memory and the prominent degeneration of basal forebrain cholinergic neurons in $\mathrm{AD}$ [17]. Despite its limited clinical efficacy, AChE inhibition has been successful for over 20 years as the best available treatment strategy for $\mathrm{AD}$. More recently, memantine has been FDA-approved for treating $\mathrm{AD}$. Memantine is the first in a class of NMDA receptor antagonists that influence neurotransmission to provide marginal improvement in memory formation and cognitive function in $\mathrm{AD}$ [18].
Other psychotropic medications are also used to treat $\mathrm{AD}$ patients symptomatically. With moderate to advanced $\mathrm{AD}$, patients frequently become agitated or develop psychotic symptoms such as paranoid ideation and auditory hallucinations. These symptoms often are improved with psychotropic medications, including atypical antipsychotics $[19,20]$ such as risperidone and olanzapine, and typical antipsychotics such as haloperidol [19-21]. These antipsychotic medications, though often helpful, unfortunately carry the risk of precipitating cerebrovascular accidents in older people [22]. Similar to the AChE inhibitors and NMDA receptor antagonists, the antipsychotic agents do not retard progression of the neurodegenerative process. Benzodiazepines sometimes are used, particularly in the acute setting, to treat agitated patients with $\mathrm{AD}$ and are also sometimes prescribed for insomnia, as circadian rhythms are frequently disrupted in $\mathrm{AD}$. Although the benzodiazepines are sometimes helpful due to their anxiolytic and sedating properties, it is usually best to avoid using them because they can exacerbate cognitive impairment $[23,24]$.

\section{Recent advances \\ Redox-active compounds}

The advances in the molecular and pathogenetic mechanisms that evolve into the final pathologic picture of $\mathrm{AD}$ provide enormous insight into possible targets for newer, and hopefully more effective, therapy. Extracts of Ginkgo biloba show antioxidant properties with reduced superoxide release in polymorphonuclear leukocytes [25]. Ginkgo constituents may act as scavengers of free radicals [26] and increase cholinergic transmission in the brain by inhibiting AChE [27], both of which may be beneficial in AD. However, clinical studies of Ginkgo have not consistently yielded positive results.

A randomized placebo-controlled trial using antioxidant therapies alpha-tocopherol, selegiline, and combination therapy showed significant delays in time to death, placement in a nursing home, development of severe dementia, or a defined severity of impairment of activities of daily living [28]. Antioxidants may ablate cognitive decline $[29,30]$, suggesting that these strategies are beneficial in reducing the risk for developing $\mathrm{AD}$. On the other hand, the beneficial effects of alphatocopherol and selegiline and other antioxidants have not always been reproduced in clinical trials [31]. It is possible that the oxidative stress pathophysiology in $\mathrm{AD}$ is so severe that conventional antioxidants have marginal or insufficient power to buffer against pathophysiologic redox metabolism. At the present time, antioxidant therapy is not recommended in $\mathrm{AD}$, although patients frequently are advised by physicians to take over-the-counter antioxidant supplements, partly 
due to the low probability that these compounds will have adverse effects.

\section{Iron chelation}

Chelation therapy offers another strategy for reducing oxidative stress. Formation of the toxic hydroxyl radical from $\mathrm{H}_{2} \mathrm{O}_{2}$ requires electron donation from $\mathrm{Cu}^{+}$or $\mathrm{Fe}^{2+}$, the latter being much more prevalent in the labile pools of cytosolic redox-active metals. In the context of $\mathrm{AD}$, the $\mathrm{A} \beta$ peptide is considered a strong redox-active agent that is capable of reducing transition metals in the cytoplasm and allowing the conversion of molecular oxygen to $\mathrm{H}_{2} \mathrm{O}_{2}$ $[9,32,33]$. The metal ion dyshomeostasis in $\mathrm{AD}$, with high levels of redox-active metals (particularly iron) being found in the affected areas of the brain, suggests chelation as a reasonable form of therapy. The use of covalent conjugation of nanoparticles with iron chelators [34] has been proposed to help overcome the limitation to chelation therapy imposed by BBB permeability. This unique approach would enable transport of chelators and chelator-metal complexes in both directions across the BBB.

\section{Non-redox-active compounds}

Numerous other compounds under development for experimental treatment of $\mathrm{AD}$ do not directly quench ROS through redox activity but are known to have downstream antioxidant effects. There is epidemiologic evidence that homocysteine is an independent risk factor for the development of dementia [35], with a plasma level of greater than $14 \mu \mathrm{M}$ causing a twofold increased risk of $\mathrm{AD}$. A number of studies, however, show that the central nervous system (CNS) is acutely sensitive to homocysteine, which is also an NMDA receptor agonist that stimulates calcium influx and promotes glutamate excitotoxicity, and causes oxidative stress and DNA damage. With its redox-active thiol residues, homocysteine can also impair the antioxidant activities of glutathione. In addition, with its ability to coordinate copper, homocysteine can promote one-electron transfer reactions with $\mathrm{H}_{2} \mathrm{O}_{2}$, resulting in the formation of the toxic hydroxyl radical. Elevated plasma homocysteine and low folate may be risk factors for the development of dementia and $\mathrm{AD}$, spurring controlled studies on the efficacy of folate supplementation and reduction of homocysteine levels on dementia and $\mathrm{AD}[36,37]$.

Other compounds that have antioxidant effects and that have been tested for efficacy in treating cognitive decline include estrogen replacement, which was shown not to be effective in treating post-menopausal $\mathrm{AD}$. In experimental studies, leuprolide, a selective gonadotropinreleasing hormone agonist that markedly reduces secretion of the gonadotropins, luteinizing hormone, and follicle-stimulating hormone, is thought to divert $\mathrm{A} \beta$ protein precursor and reduce brain amyloid and ROS formation [38]. Luteinizing hormone is found to be elevated in $\mathrm{AD}$ due to the negative feedback stimulation by low gonadal steroid levels. In clinical studies, female $\mathrm{AD}$ patients treated with leuprolide showed stabilization of cognitive impairment and activities of daily living.

Leptin is a centrally acting hormone that controls AMP kinase, maintains lipid levels, and regulates glycogen synthase kinase 3, which modulates tau phosphorylation. Leptin has been shown in vitro and in vivo to reduce extracellular $A \beta$ and neuronal tau phosphorylation as well as improve cognitive performance of transgenic mouse models of $\mathrm{AD}$. In humans, weight loss preceding the onset of $\mathrm{AD}$ dementia is inversely proportionate in severity to leptin levels, suggesting that leptin deficiency contributes to systemic and CNS abnormalities in AD and that this hormone may be a novel therapeutic agent in $\mathrm{AD}$, with antioxidant effects through its modulation of intracellular signaling cascades [39].

Insight into the role of metabolic agents, which are influenced by underlying genetics, has emerged. There is a significant increased risk of developing $\mathrm{AD}$ in people who have the gene for apolipoprotein E4 (ApoE4), a protein that helps carry circulating cholesterol. A specific fragment formed rapidly from ApoE4 plays a role in oxidative stress by adversely affecting mitochondrial function. It is thought also that poor glucose use and insulin resistance, as seen in type 2 diabetes mellitus, play a role in AD $[40,41]$. Preliminary results with the oral hypoglycemic agent rosiglitazone in patients with mild to moderate $\mathrm{AD}$ show that patients who do not carry the ApoE4 gene show improvement whereas patients with ApoE4 do not respond [42].

We are cautiously optimistic about the potential therapeutic value of dimebon, a new candidate therapeutic agent for AD. Dimebon has been shown to inhibit degeneration of neurons and works through a novel mechanism of action, improving mitochondrial function. In a phase II randomized double-blind placebo-controlled trial with mild to moderate $\mathrm{AD}$, dimebon-treated patients showed statistically significant improvement in cognition, activities of daily living, behavior, and overall function [43]. It was found to have a positive impact on caregiver stress, reducing the amount of time they needed to spend assisting patients. It also showed a favorable side-effect profile. Larger scale clinical trials of dimebon are clearly warranted.

\section{Implications for clinical practice}

While cholinesterase inhibitor and NMDA receptor antagonists such as memantine, alone or in 
combination, continue to be prescribed for patients with $\mathrm{AD}$ along with the promotion of proper nutrition and occupational health [44], we feel we are on the threshold of a new era in $\mathrm{AD}$ therapy in which therapies will slow the rate of disease progression. Even for those who still believe that the aim of therapy should be to reduce the pathologic end result that characterizes the disease, the hormone leptin shows promise in reducing extracellular $\mathrm{A} \beta$, and the use of covalently conjugated nanoparticles with iron chelators to solubilize $\mathrm{A} \beta$ may overcome the limitations of chelation therapy posed by the BBB. Leuprolide therapy, and especially its temporal relationship to menopause, may prove to be the treatment of choice in preventing $\mathrm{AD}$ in women. Most of all, the relationship between vascular and cognitive health and the role played by the presence of glucose intolerance on first one and then the other are yielding a new and exciting approach to $\mathrm{AD}$ therapy, which may be mechanistically based in oxidative stress. With improved understanding of $\mathrm{AD}$ pathogenesis, there is little doubt that the focus of $\mathrm{AD}$ therapy will shift to target what appears to be a key player in disease evolution, namely oxidative stress. In this respect, promising compounds like dimebon warrant further development.

We have come a long way in our treatment strategies for $\mathrm{AD}$. Acknowledging that it is the molecular mechanisms instrumental in the evolution of the disease, not the final pathologic result [45], that should be the target is a very big step in a promising direction. This is a very exciting time for the field of Alzheimer's research and should prove fruitful.

\section{Abbreviations}

$\mathrm{A} \beta$, amyloid-beta; ACh, acetylcholine; AChE, acetylcholinesterase; $\mathrm{AD}$, Alzheimer's disease; ApoE4, apolipoprotein E4; $\mathrm{BBB}$, blood-brain barrier; CNS, central nervous system; FDA, US Food and Drug Administration; NMDA, $N$-methyl-D-aspartate; RAGE, receptor for advanced glycation endproducts; ROS, reactive oxygen species.

\section{Competing interests}

MAS is a paid consultant and/or receives lecture fees from Anavex Life Sciences Corp (Geneva, Switzerland), Medivation (San Francisco, CA, USA), and Neurotez (Bridgewater, NJ, USA).

\section{Acknowledgments}

Work in the authors' laboratories is supported by the National Institutes of Health (R01 AG026151 and R01 AG031852) and the Alzheimer's Association. MWM is supported by the NEURAD PhD Graduate School, a Marie-Curie fellowship awarded by the European Union.

\section{References}

I. Russell RL, Siedlak SL, Raina AK, Bautista JM, Smith MA, Perry G: Increased neuronal glucose-6-phosphate dehydrogenase and sulfhydryl levels indicate reductive compensation to oxidative stress in Alzheimer disease. Arch Biochem Biophys 1999. 370:236-9.

2. Mastrogiacomo F, Bergeron C, Kish SJ: Brain alpha-ketoglutarate dehydrogenase complex activity in Alzheimer's disease. J Neurochem 1993, 6 I:2007-I4.

3. Moreira PI, Siedlak SL, Wang X, Santos MS, Oliveira CR, Tabaton M, Nunomura A, Szweda LI, Aliev G, Smith MA, Zhu X, Perry G: Autophagocytosis of mitochondria is prominent in Alzheimer disease. J Neuropathol Exp Neurol 2007, 66:525-32.

4. Simonian NA, Hyman BT: Functional alterations in Alzheimer's disease: selective loss of mitochondrial-encoded cytochrome oxidase mRNA in the hippocampal formation. J Neuropathol Exp Neurol 1994, 53:508-12.

5. Yates CM, Butterworth J, Tennant MC, Gordon A: Enzyme activities in relation to $\mathrm{pH}$ and lactate in postmortem brain in Alzheimer-type and other dementias. J Neurochem 1990, 55: 1624-30.

6. Smith MA, Harris PL, Sayre LM, Perry G: Iron accumulation in Alzheimer disease is a source of redox-generated free radicals. Proc Natl Acad Sci U S A 1997, 94:9866-8.

7. Sayre LM, Perry G, Harris PL, Liu Y, Schubert KA, Smith MA: In situ oxidative catalysis by neurofibrillary tangles and senile plaques in Alzheimer's disease: a central role for bound transition metals. J Neurochem 2000, 74:270-9.

8. Bondy SC, Guo-Ross SX, Truong AT: Promotion of transition metal-induced reactive oxygen species formation by betaamyloid. Brain Res 1998, 799:9|-6.

9. Huang X, Atwood CS, Hartshorn MA, Multhaup G, Goldstein LE, Scarpa RC, Cuajungco MP, Gray DN, Lim J, Moir RD, Tanzi RE, Bush Al: The A beta peptide of Alzheimer's disease directly produces hydrogen peroxide through metal ion reduction. Biochemistry (Mosc) 1999, 38:7609-16.

10. Zhu X, Castellani RJ, Takeda A, Nunomura A, Atwood CS, Perry G, Smith MA: Differential activation of neuronal ERK, JNK/SAPK and p38 in Alzheimer disease: the 'two hit' hypothesis. Mech Ageing Dev 200I, I 23:39-46.

II. Zhu X, Lee HG, Perry G, Smith MA: Alzheimer disease, the two-hit hypothesis: an update. Biochim Biophys Acta 2007, I 772:494-502.

12. Zhu X, Raina AK, Perry G, Smith MA: Alzheimer's disease: the two-hit hypothesis. Lancet Neurol 2004, 3:219-26.

13. Zlokovic BV: The blood-brain barrier in health and chronic neurodegenerative disorders. Neuron 2008, 57:I78-20I.

14. Bowman GL, Kaye JA, Moore M, Waichunas D, Carlson NE, Quinn JF: Blood-brain barrier impairment in Alzheimer disease: stability and functional significance. Neurology 2007, 68:|809-|4.

15. Shah S, Reichman WE: Treatment of Alzheimer's disease across the spectrum of severity. Clin Interv Aging 2006, I:| 3 | -42.

16. Cummings JL, Frank JC, Cherry D, Kohatsu ND, Kemp B, Hewett L, Mittman B: Guidelines for managing Alzheimer's disease: part II. treatment. Am Fam Physician 2002, 65:2525-34.

17. Munoz-Torrero D: Acetylcholinesterase inhibitors as diseasemodifying therapies for Alzheimer's disease. Curr Med Chem 2008, I 5:2433-55.

18. Farlow MR, Graham SM, Alva G: Memantine for the treatment of Alzheimer's disease: tolerability and safety data from clinical trials. Drug Saf 2008, 31:577-85.

19. Ballard C, Waite J: The effectiveness of atypical antipsychotics for the treatment of aggression and psychosis in Alzheimer's disease. Cochrane Database Syst Rev 2006, CD003476.

20. Grossman F, Okamoto A, Turkoz I, Gharabawi G: Risperidone in the treatment of elderly patients with psychosis of Alzheimer's disease and related dementias. J Am Geriatr Soc 2004, 52:852-3. 
21. Salzman C: Treatment of the agitation of late-life psychosis and Alzheimer's disease. Eur Psychiatry 200I, I6(Suppl I): 25s-28s.

22. Gill SS, Rochon PA, Herrmann N, Lee PE, Sykora K, Gunraj N, Normand SL, Gurwitz JH, Marras C, Wodchis WP, Mamdani M: Atypical antipsychotic drugs and risk of ischaemic stroke: population based retrospective cohort study. BMJ 2005, 330:445.

23. Attard A, Ranjith G, Taylor D: Delirium and its treatment. CNS Drugs 2008, 22:63I-44.

24. Karlsson I: Drugs that induce delirium. Dement Geriatr Cogn Disord 1999, 10:412-5

25. Wada K, Ishigaki S, Ueda K, Take Y, Sasaki K, Sakata M, Haga M: Studies on the constitution of edible and medicinal plants. I. Isolation and identification of 4-O-methylpyridoxine, toxic principle from the seed of Ginkgo biloba L. Chem Pharm Bull (Tokyo) 1988, 36: 1779-82.

26. Oyama Y, Fuchs PA, Katayama N, Noda K: Myricetin and quercetin, the flavonoid constituents of Ginkgo biloba extract, greatly reduce oxidative metabolism in both resting and $\mathrm{Ca}(2+)$-loaded brain neurons. Brain Res 1994, 635:125-9.

27. DeFeudis F: Ginkgo Biloba Extract (Egb76I) Pharmacological Act and Clinical Application. Paris: Elsevier; 1991.

28. Sano M, Ernesto C, Thomas RG, Klauber MR, Schafer K, Grundman M, Woodbury P, Growdon J, Cotman CW, Pfeiffer E, Schneider LS, Thal LI: A controlled trial of selegiline, alphatocopherol, or both as treatment for Alzheimer's disease. The Alzheimer's Disease Cooperative Study. N Engl J Med 1997, 336:1216-22.

29. Jama JW, Launer LJ, Witteman JC, den Breeijen JH, Breteler MM, Grobbee DE, Hofman A: Dietary antioxidants and cognitive function in a population-based sample of older persons. The Rotterdam Study. Am J Epidemiol 1996, 144:275-80.

30. Perrig WJ, Perrig P, Stähelin HB: The relation between antioxidants and memory performance in the old and very old. J Am Geriatr Soc 1997, 45:718-24.

31. Isaac MG, Quinn R, Tabet N: Vitamin E for Alzheimer's disease and mild cognitive impairment. Cochrane Database Syst Rev 2008, CD002854.

32. Hayashi T, Shishido N, Nakayama K, Nunomura A, Smith MA, Perry G, Nakamura M: Lipid peroxidation and 4-hydroxy-2nonenal formation by copper ion bound to amyloid-beta peptide. Free Radic Biol Med 2007, 43: I552-9.

33. Nakamura M, Shishido N, Nunomura A, Smith MA, Perry G, Hayashi Y, Nakayama K, Hayashi T: Three histidine residues of amyloid-beta peptide control the redox activity of copper and iron. Biochemistry (Mosc) 2007, 46: $12737-43$.

34. Liu G, Men P, Harris PL, Rolston RK, Perry G, Smith MA: Nanoparticle iron chelators: a new therapeutic approach in
Alzheimer disease and other neurologic disorders associated with trace metal imbalance. Neurosci Lett 2006, 406:189-93.

35. Seshadri S, Beiser A, Selhub J, Jacques PF, Rosenberg $I H$, D'Agostino RB, Wilson PW, Wolf PA: Plasma homocysteine as a risk factor for dementia and Alzheimer's disease. $N$ Engl J Med 2002, 346:476-83.

36. Aisen PS, Jin S, Thomas RG, Sano M, Diaz-Arrastia R, Thal L; Alzheimer's Disease Cooperative Study NIA: S3-02-0I: ADCS homocysteine trial. Alzheimers Dement 2007, 3(Suppl I): SI 99.

37. Viswanathan A, Raj S, Greenberg SM, Stampfer M, Campbell S, Hyman BT, Irizarry MC: Plasma Abeta, homocysteine, and cognition: the Vitamin Intervention for Stroke Prevention (VISP) trial. Neurology 2009, 72:268-72.

38. Casadesus G, Webber KM, Atwood CS, Pappolla MA, Perry G, Bowen RL, Smith MA: Luteinizing hormone modulates cognition and amyloid-beta deposition in Alzheimer APP transgenic mice. Biochim Biophys Acta 2006, I 762:447-52.

39. Greco SJ, Sarkar S, Johnston JM, Zhu X, Su B, Casadesus G, Ashford JW, Smith MA, Tezapsidis N: Leptin reduces Alzheimer's disease-related tau phosphorylation in neuronal cells. Biochem Biophys Res Commun 2008, 376:536-4I.

40. Alexander GE, Chen K, Pietrini P, Rapoport SI, Reiman EM: Longitudinal PET evaluation of cerebral metabolic decline in dementia: a potential outcome measure in Alzheimer's disease treatment studies. Am J Psychiatry 2002, I59:738-45.

41. Watson GS, Craft S: The role of insulin resistance in the pathogenesis of Alzheimer's disease: implications for treatment. CNS Drugs 2003, 17:27-45.

42. Risner ME, Saunders AM, Altman JF, Ormandy GC, Craft S, Foley IM, Zvartau-Hind ME, Hosford DA, Roses AD: Efficacy of rosiglitazone in a genetically defined population with mildto-moderate Alzheimer's disease. Pharmacogenomics J 2006, 6:246-54.

43. Doody RS, Gavrilova SI, Sano M, Thomas RG, Aisen PS, Bachurin SO, Seely L, Hung D: Effect of dimebon on cognition, activities of daily living, behaviour, and global function in patients with mild-tomoderate Alzheimer's disease: a randomised, double-blind, placebo-controlled study. Lancet 2008, 372:207-I5.

FI000 Factor 3.0 Recommended Evaluated by Elio Scarpini 28 Oct 2008

44. Wu S, Liang J, Miao D: Physical activity and cognitive function in Alzheimer disease. JAMA 2009, 301:273; author reply 273-74.

45. Castellani RJ, Lee HG, Zhu X, Nunomura A, Perry G, Smith MA: Neuropathology of Alzheimer disease: pathognomonic but not pathogenic. Acta Neuropathol (Berl) 2006, I I I:503-9. 